\title{
基于生物条形码的粘蛋白和特定细胞电化学发光 适配体生物传感方法研究
}

\author{
王晓飞, 漆红兰 ${ }^{*}$, 张成孝 \\ 陕西师范大学化学化工学院, 应用表面与胶体化学教育部重点实验室, 陕西省生命分析化学重点实验室, 西安 710062 \\ *通讯作者, E-mail: honglanqi@snnu.edu.cn
}

收稿日期: 2020-09-29; 接受日期: 2020-11-02; 网络版发表日期: 2020-11-12

国家自然科学基金(编号: 21775097, 21775098)、中央高校基础研究经费(编号: GK201801006)资助项目

摘要本文基于适配体识别和生物条形码放大策略, 以MCF-7细胞和粘蛋白 (MUC1)为目标物, MUC1的特异 性适配体 (rcDNA) 为分子识别物质, $\mathrm{Ru}(\mathrm{phen})_{3}{ }^{2+}$ 为信号物质, rcDNA通过巯基自组装于金电极表面作为传感界面, 发卡DNA (hpDNA) 和rcDNA通过颈基自组装在金纳米粒子(AuNP)表面合成的 hpDNA/AuNP/rcDNA为生物条形 码探针, 建立了测定MUC1 和特定细胞的电化学发光适配体生物传感新方法. 当目标物被传感界面上的rcDNA俘 获后, 进而与生物条形码探针形成夹心复合物, Ru(phen $)_{3}{ }^{2+}$ 嵌入 hpDNA 中. 在共反应剂的存在和 $+0.95 \mathrm{~V}$ 恒电位下 测量电化学发光强度. 电化学发光强度的变化值与 MUC1和MCF-7细胞浓度的对数在 $4 \sim 800 \mathrm{pg} / \mathrm{mL}$ 和 $30 \sim 5.0 \times 10^{4}$ cells $/ \mathrm{mL}$ 范围内呈良好的线性关系, 检出限分别为 $0.5 \mathrm{pg} / \mathrm{mL}$ 和 9 cells $/ \mathrm{mL}$. 将该法应用于监测两种物质刺激下 MCF-7细胞表面MUC1含量的变化, 发现芹黄素刺激下细胞表面MUC1含量降低, 而过氧化氢刺激下细胞表面 MUC1含量不变.

关键词电化学发光, 生物传感, 细胞分析, 粘蛋白, 药物刺激

\section{1 引言}

细胞是生命活动的基本单位. 细胞表面蛋白质参 与细胞生长、增殖等重要的生物学过程. 监测细胞表 面蛋白质的含量变化在细胞生物学研究和疾病诊断中 具有重要意义 ${ }^{[1,2]}$. 粘蛋白 (MUC1) 是一种跨膜蛋白, 其在细胞表面的表达量与肿瘤细胞侵袭、转移及信号 转导等过程息息相关, 可作为乳腺癌、前列腺癌等多 种癌症早期诊断的生物标志物 ${ }^{[3]}$. 已报道测定MUC1 的方法有酶联免疫法 ${ }^{[4]}$ 、比色法 ${ }^{[5]}$ 、苂光法 ${ }^{[6,7]}$ 、电化
学法 ${ }^{[8,9]}$ 、和电化学发光法 (ECL) ${ }^{[10 \sim 12]}$ 等. 电化学发光 是在电极上施加一定的电压使电极反应产物之间或电 极反应产物与溶液中某组分进行化学反应而产生的一 种光辐射 ${ }^{[13 \sim 15]}$. 根据电化学发光强度进行分析的方法 称为电化学发光分析法. 电化学发光分析法因其高灵 敏度在MUC1的分析检测中得到人们的关注. 例如鞠 熀先教授等人 ${ }^{[12]}$ 利用聚合物点标记适配体为电化学 发光探针, 建立了高灵敏度检测细胞表面MUC1含量 的电化学发光分析法. 因细胞大的体积和对电子传递 的阻碍作用, 建立高灵敏度的电化学发光分析法, 进

引用格式: Wang X, Qi H, Zhang C. Electrogenerated chemiluminescence aptamer-based biosensing for the determination of mucin and specific cells based on biobar-code amplification. Sci Sin Chim, 2021, 51: 388-394, doi: 10.1360/SSC-2020-0193 
行外界刺激下细胞表面MUC1含量的实时监测，对了 解MUC1的调控机制和药物䇻选具有重要意义.

本研究旨在建立一种高灵敏度电化学发光适配体 生物传感分析新方法，以监测物质刺激下细胞表面蛋 白质含量的动态变化, 测定原理如图1所示. 以MCF-7 细胞为目标细胞, MUC1为目标蛋白质, MUC1的特异 性适配体 (rcDNA) 为分子识别物质, $\mathrm{Ru}(\mathrm{phen})_{3}{ }^{2+}$ 为信 号物质，末端为颈基 $\mathrm{rcDNA}$ 自组装于金电极表面作为 传感界面，两种末端为颈基的发卡DNA (hpDNA) 和 rcDNA通过統基自组装在金纳米粒子(AuNP)表面合 成的 $h p D N A / A u N P / r c D N A$ 为生物条形码探针, 建立了 测定MUC1和特定细胞的高灵敏度电化学发光适配体 生物传感新方法. 当MUC1或MCF-7细胞被传感界面 上的rcDNA俘获后，进而与生物条形码探针形成夹心 复合物, Ru(phen $)_{3}{ }^{2+}$ 嵌入hpDNA中. 在共反应剂TPA的 存在下, 在 $+0.95 \mathrm{~V}$ 恒电位下测量电化学发光强度, 建 立了一种“增强型”生物传感分析新方法，进行MUC1 和特定细胞的分析检测。该方法进一步应用于监测芹 黄素和过氧化氢 $\left(\mathrm{H}_{2} \mathrm{O}_{2}\right)$ 刺激下MCF-7细胞表面MUC1 含量的动态变化.

\section{2 实验部分}

\section{1 试剂}

MUC1购自Abnova公司(美国). 三-(2-羧乙基)膦盐 酸盐(TCEP)、6-颈基-1-己醇( MCH)、芹黄素、二氯

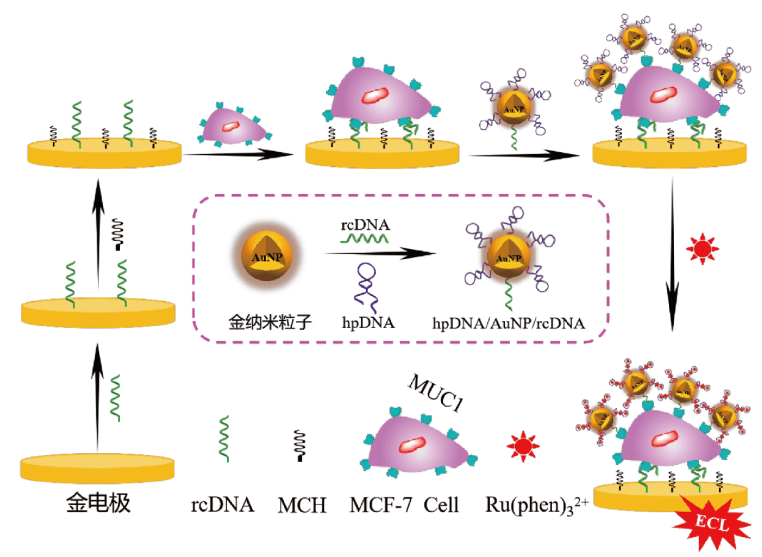

图 1 电化学发光适配体生物传感方法检测MCF-7细胞示 意图 (网络版彩图)

Figure 1 Scheme of the ECL biosensing for the determination of MCF-7 cells based on the aptamer recognition and bio-bar-code amplification (color online).
三 $\left(1,10\right.$ - 菲罗啉)钉(II)水合物 $\left(\mathrm{Ru}(\mathrm{phen})_{3} \mathrm{Cl}_{2}\right)$ 、双 $\left(2,2^{\prime}\right.$ 联吡啶)-4 ' - 甲基-4-羒基吡啶-钉- $N$-琥珀酰亚胺酯 (Ru1)和乙二胺四乙酸钠 $\left(\mathrm{Na}_{2} \mathrm{EDTA}\right)$ 均购自 Sigma-Aldrich公司(美国). 三正丙胺(TPA)、氯金酸 $(\geq 99.9 \%$, $\left.\mathrm{HAuCl}_{4} \cdot 3 \mathrm{H}_{2} \mathrm{O}\right)$ 、磷酸二氢钠 $\left(\mathrm{NaH}_{2} \mathrm{PO}_{4}\right)$ 、磷酸氢二钠 $\left(\mathrm{Na}_{2} \mathrm{HPO}_{4}\right)$ 、醋酸钠 $(\mathrm{NaAc})$ 和氯化钾 $(\mathrm{KCl})$ 均购自国 药化学试剂有限公司(中国). MCF-7细胞、HeLa细 胞、A549细胞、HCT116细胞和RAW264.7细胞均购 自中国科学院上海细胞库(中国). 碘化丙啶(PI)和异硫 氧酸荧光素标记的膜联蛋白V (Annexin V-FITC)购自 上海碧云天生物技术有限公司(中国). MUC1适配体 (rcDNA, 序列为 5'-SH-GCA-GTT-CCT-TTG-GAT-ACCCTG-3') ${ }^{[16]}$ 和发卡DNA(hpDNA, 序列为 5'-GCG-CAAGAG-TTC-TTT-TGA-ACT-CTT-GCG-CTT-TTT-HS-3') 购自上海生工生物技术有限公司(中国). $10 \mathrm{mM}$ 磷酸

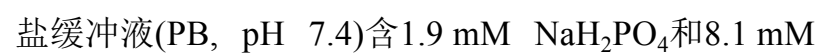
$\mathrm{Na}_{2} \mathrm{HPO}_{4}$. $0.05 \mathrm{M}$ 磷酸盐缓冲液( $\mathrm{PB}, \mathrm{pH}$ 7.4)含 0.0095 $\mathrm{M} \mathrm{NaH}_{2} \mathrm{PO}_{4}$ 和 $0.0405 \mathrm{M} \mathrm{Na}_{2} \mathrm{HPO}_{4} \cdot 0.1 \mathrm{M}$ 磷酸盐缓冲液 (PBS, pH 7.4, 含0.019 M NaH $\mathrm{PO}_{4}, 0.081 \mathrm{M} \mathrm{Na}_{2} \mathrm{HPO}_{4}$ 和0.1 M KCl). 超纯水 $(18.2 \mathrm{M} \Omega \cdot \mathrm{cm})$.

\section{2 仪器}

MPI-E型电致化学发光分析仪(西安瑞迈分析仪器 有限公司, 中国). 透射电子显微镜(TEM, JEM-2100, 日 本JEOL). 紫外可见分光光度计(UV-2450, 岛津公司, 日本), 流式细胞仪(FACSCalibur, BD公司, 美国). 电 感耦合等离子-质谱仪(M90, 布鲁克, 德国). 实验中采 用三电极体系, 工作电极为直径 $2.0 \mathrm{~mm}$ 的金电极, 参 比电极为 $\mathrm{Ag} / \mathrm{AgCl}$ (饱和 $\mathrm{KCl}$ )电极, 对电极为铂丝电极.

\section{3 生物条形码探针hpDNA/AuNP/rcDNA的制备}

根据参考文献 ${ }^{[17]}$ 的方法, 采用柠檬酸三钠还原法 制备了金纳米粒子(AuNP). Ru1标记rc-DNA（Ru1rcDNA)、hpDNA/AuNP/rcDNA和Ru1-hpDNA/AuNP/ rcDNA 的制备参考文献 ${ }^{[18,19]}$ 的方法. 其中, hpDNA/ AuNP/rcDNA中使用hpDNA和rcDNA. Ru1-hpDNA/ AuNP/rcDNA中使用Ru1-hpDNA和rcDNA. 具体步骤 见支持信息.

\section{4 电化学发光细胞分析}

金电极按照常规方法处理(具体步骤见支持信息). 
将处理好的金电极浸入 $100 \mu \mathrm{L}, 10 \mu \mathrm{M} r \mathrm{rDNA}$ 溶液中, 室温下放置 $3 \mathrm{~h}$. 然后将其浸入 $100 \mu \mathrm{L}, 1 \mathrm{mM} \mathrm{MCH}$ 溶 液, 室温下放置30 min, 获得 $\mathrm{rcDNA}$ 修饰的金电极.

将得到的修饰电极依次浸入不同浓度的MUC1溶 液(或细胞悬浮液)和 $0.4 \mathrm{nM} \mathrm{hpDNA} / \mathrm{AuNPs} / \mathrm{rcDNA}$ 探 针溶液中, $37^{\circ} \mathrm{C}$ 下反应 $60 \mathrm{~min}$. 最后, 获得的修饰电极 在 $50 \mu \mathrm{M} \mathrm{Ru}(\text { phen })_{3}{ }^{2+}$ 溶液中反应 $50 \mathrm{~min}$. 每一步都用 $10 \mathrm{mM}$ PB (pH 7.4) 冲洗电极. 监测药物刺激下MCF7 细胞表面MUC1的含量变化时, MCF-7细胞分别与 含有 $72 \mu \mathrm{M}$ 芹黄素或 $200 \mu \mathrm{M} \mathrm{H} \mathrm{O}_{2}$ 的细胞培养液(Dulbecco's modified Eagle's medium, DMEM, Hyclone, 美国)在细胞培养箱中 $37^{\circ} \mathrm{C}$ 培养不同时间. 其他条件 同上.

施加 $+0.95 \mathrm{~V}$ 的恒电位, 在含 $50 \mathrm{mM}$ TPA的 $0.1 \mathrm{M}$ PBS (pH 7.4) 溶液中测定电化学发光信号. 用电化学发 光强度变化值 $\left(\Delta I=I_{\mathrm{s}}-I_{0}\right)$ 对 MUC1或细胞进行定量分 析. $I_{0}$ 为空白电化学发光强度. $I_{\mathrm{s}}$ 指与含有目标物溶液 反应后所获得的电化学发光强度.

\section{3 结果与讨论}

\section{1 探针的表征}

首先对合成的 $h p D N A / A u N P / r c D N A$ 进行表征. 紫 外可见吸收光谱图(图2(A)) 显示hpDNA/AuNP/rcDNA 在 $254 \mathrm{~nm}$ 和 $522 \mathrm{~nm}$ 处出现 2 个吸收峰, 分别对应DNA 和AuNP的特征吸收峰. 根据AuNP的浓度计算可得 hpDNA/AuNP/rcDNA的浓度为 $3.2 \mathrm{nM}$. 在 $0.2 \mathrm{M} \mathrm{NaCl}$ 存在下的盐诱导聚集实验发现(图2(B)), AuNP溶液由 酒红色变为黑色, 说明发生了明显的聚沉; 而hpDNA/ AuNP/rcDNA溶液均为酒红色. 单独的AuNP的平均粒 径为 $13.14 \pm 0.12 \mathrm{~nm}$ (图2(C)), hpDNA/AuNP/rcDNA的 平均粒径为 $13.59 \pm 0.47 \mathrm{~nm}$ (图2(D)), 说明 $\mathrm{AuNP}$ 与DNA 结合后粒子尺寸稍有增加且在 $h p D N A / A u N P / r c D N A$ 外围观察到明显的DNA层 ${ }^{[20,21]}$. 以上结果表明已成功 合成了 $h p D N A / A u N P / r c D N A$ 探针.

\section{2 基于生物条形码的电化学发光适配体生物传 感方法的可行性研究}

我们构建基于生物条形码探针的电化学发光适配 体生物传感分析新方法, 进行细胞表面蛋白质的含量 分析. 分别以 MUC1和MCF-7细胞为目标分析物, 考察

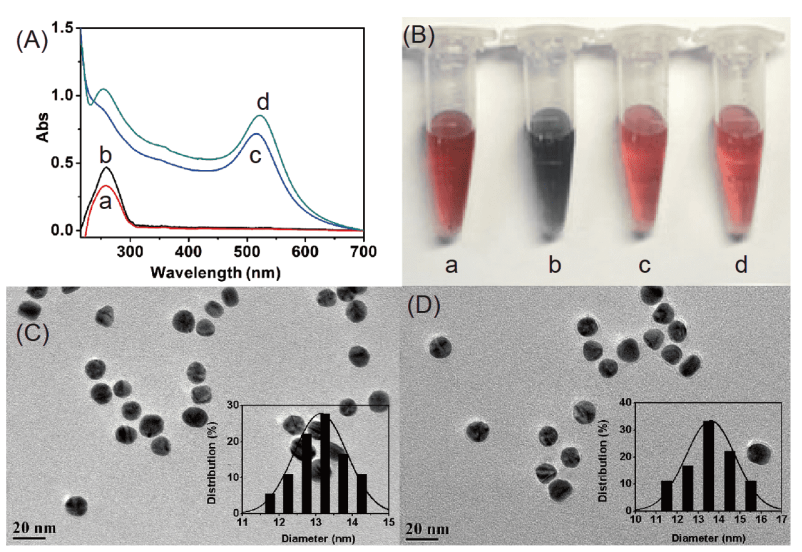

图 2 (A) (a) $10 \mu \mathrm{M} \mathrm{rcDNA;} \mathrm{(b)} 10 \mu \mathrm{M}$ hpDNA; (c) $2.7 \mathrm{nM}$ AuNP; (d) $3.2 \mathrm{nM}$ hpDNA/AuNP/rcDNA的紫外可见吸收光

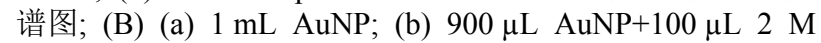
$\mathrm{NaCl}$; (c) $1 \mathrm{~mL}$ hpDNA/AuNP/rcDNA; (d) $900 \mu \mathrm{L}$ hpDNA/ AuNP/rcDNA $+100 \mu \mathrm{L} 2 \mathrm{M} \mathrm{NaCl}$ 溶液明场照片; (C) AuNP的 透射电镜图; 内插图: AuNP的粒径分布图; (D) hpDNA/ AuNP/rcDNA的透射电镜图; 内插图: hpDNA/AuNP/rcDNA 的粒径分布图 (网络版彩图)

Figure 2 (A) UV-vis absorption spectra of (a) $10 \mu \mathrm{M}$ rcDNA; (b) $10 \mu \mathrm{M}$ hpDNA; (c) $2.7 \mathrm{nM}$ AuNP; (d) $3.2 \mathrm{nM}$ hpDNA/AuNP/rcDNA; (B) Photographs of (a) $1 \mathrm{~mL}$ AuNP; (b) $900 \mu \mathrm{L}$ AuNP+100 $\mu \mathrm{L} 2 \mathrm{M}$ $\mathrm{NaCl}$; (c) $1 \mathrm{~mL}$ hpDNA/AuNP/rcDNA; (d) $900 \mu \mathrm{L}$ hpDNA/ AuNP/ rcDNA $+100 \mu \mathrm{L} 2 \mathrm{M} \mathrm{NaCl}$; (C) TEM image of AuNP. Inset: size distribution of the AuNP from the TEM image; (D) TEM image of the hpDNA/AuNP/rcDNA. Inset: size distribution of the hpDNA/AuNP/ rcDNA from the TEM image (color online).

方法的可行性. 当不存在MUC1时, 反应后的电极在 $+0.9 \mathrm{~V}$ 处产生一弱的电化学发光信号 (2232 (a.u.)); 存 在 $20 \mathrm{pg} / \mathrm{mL}$ MUC1时, 电化学发光信号增加至5501(a.u.). 继续增加MUC1浓度至 $200 \mathrm{pg} / \mathrm{mL}$, 电化学发光强度继

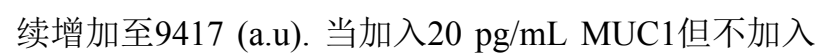
hpDNA/AuNP/rcDNA探针时, 记录到弱的电化学发光 信号 (2414 (a.u.)). 以MCF-7细胞为目标分析物, 基于 rcDNA对MCF-7细胞表面的MUC1 的选择性结合, 建 立了测定 MCF-7细胞的新方法. 当 MCF-7细胞从 $5.0 \times 10^{2}$ cells $/ \mathrm{mL}$ 增加到 $1.0 \times 10^{4}$ cells $/ \mathrm{mL}$ 时, 电化学发 光强度从5629 (a.u.)增加至8804 (a.u.) (图3). 说明该方 法可用于MUC1和MCF-7细胞的电化学发光分析检测.

\section{3 实验条件的优化}

以MCF-7细胞为目标分析物，优化了电压、适配 体修饰电极与MCF-7细胞的结合时间以及电化学发光 信号探针. 选择施加电压 $+0.95 \mathrm{~V}$ 和结合时间 $60 \mathrm{~min}$ 为 最佳实验条件(图S1). 

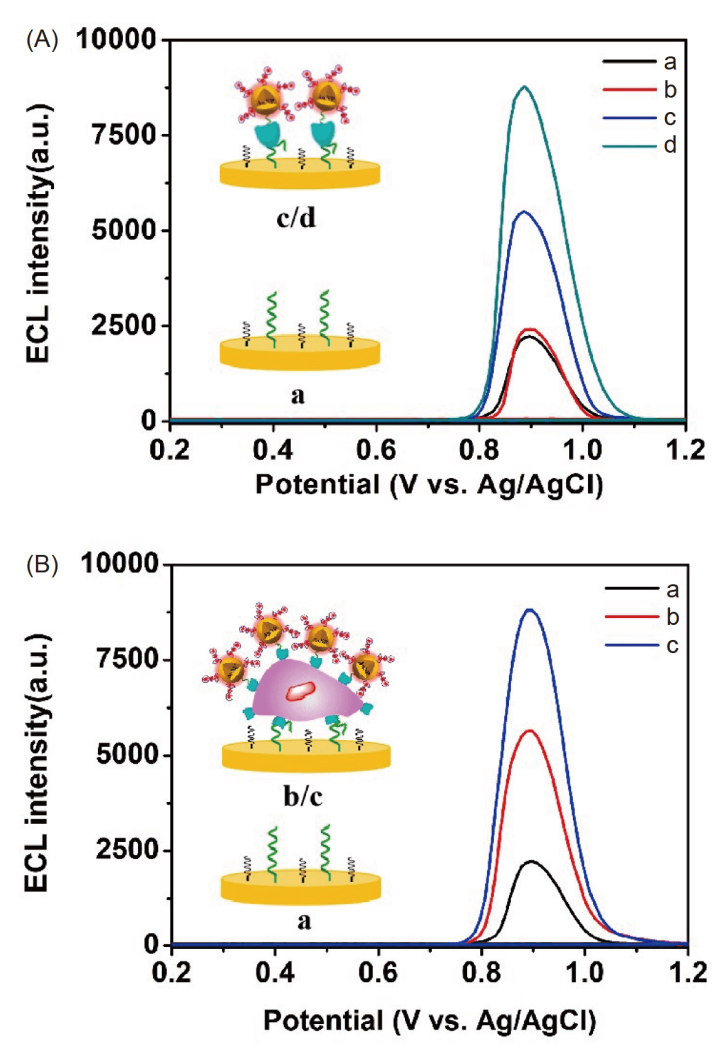

图 3 电化学发光适配体生物传感方法检测不同浓度 MUC1(A)和不同浓度MCF-7细胞(B)的电化学发光强度-电 位曲线图 (网络版彩图)

Figure 3 (A) ECL intensity vs. potential profiles for different concentrations of MUC1: (a) blank, (b) $20 \mathrm{pg} / \mathrm{mL} \mathrm{MUC1} \mathrm{in} \mathrm{the}$ absence of hpDNA/AuNP/rcDNA, $20 \mathrm{pg} / \mathrm{mL}$ MUC1 (c) and 200 $\mathrm{pg} / \mathrm{mL}$ MUC1 (d) in the presence of hpDNA/AuNP/rcDNA, respectively. (B) ECL intensity vs. potential profiles for different concentrations of MCF-7 cells: (a) blank, $5.0 \times 10^{2} \mathrm{MCF}-7$ cells $/ \mathrm{mL}$ (b) and $1.0 \times 10^{4} \mathrm{MCF}-7$ cells $/ \mathrm{mL}$ (c), respectively (color online).

考察Ru1-rcDNA、Ru1-hpDNA/AuNP/rcDNA和 $\mathrm{Ru}(\mathrm{phen})_{3}{ }^{2+}$ 嵌入 hpDNA/AuNP/rcDNA 三种不同探针 对 MCF-7细胞的电化学发光响应(图S2). 对于 Ru1rcDNA，空白电化学发光强度较弱 (1701 (a.u.)), 当

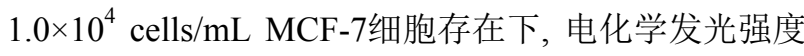
增加至3152 (a.u.). 对于Ru1-hpDNA/AuNP/rcDNA, 空 白电化学发光强度为 2222 (a.u.), 与 $1.0 \times 10^{4} \mathrm{cells} / \mathrm{mL}$ MCF-7细胞反应后, 电化学发光强度增加至6723 (a.u.). 对于 $\mathrm{Ru}(\mathrm{phen})_{3}{ }^{2+}$ 嵌入 $\mathrm{hpDNA} / \mathrm{AuNP} / \mathrm{rcDNA}$, 空白电化 学发光强度为 2856 (a.u.), 与 $1.0 \times 10^{4}$ cells $/ \mathrm{mL}$ MCF-7 细胞反应后, 电化学发光强度增加至11646 (a.u.). $\mathrm{Ru}(\mathrm{phen})_{3}^{2+}$ 嵌入 $\mathrm{hpDNA} / \mathrm{AuNP} / \mathrm{rcDNA}$ 作为电化学发光 探针引起的电化学发光强度变化 $(\Delta I=8790$ (a.u.)) 远远
高于以Ru1-rcDNA ( $\Delta I=1451$ (a.u.))和Ru1-hpDNA/ $\operatorname{AuNP} / \mathrm{rcDNA}(\Delta I=4501$ (a.u.))为探针引起的电化学发 光强度变化. 此外, 利用电感耦合等离子-质谱法表征 三种探针与细胞结合后单个MCF-7细胞表面钓原子的 含量. 单个MCF-7细胞表面钓原子的含量分别为 0.02 pg/cell (Ru1-rcDNA)、0.08 pg/cell (Ru1-hpDNA/ AuNP/rcDNA)和0.3 pg/cell (Ru(phen) ${ }_{3}{ }^{2+}$ 嵌入 hpDNA/ $\mathrm{AuNP} / \mathrm{rcDNA})$. 以下选择 $\mathrm{Ru}(\mathrm{phen})_{3}{ }^{2+}$ 嵌入 hpDNA/ AuNP/rcDNA作为电化学发光探针.

\section{4 电化学发光适配体生物传感方法检测MUC1 和MCF-7细胞}

在优化的实验条件下, 考察该电化学发光适配体 生物传感方法对 MUC1和MCF-7细胞的分析特性(图 S3). 电化学发光强度的变化值与MUC1浓度的对数在 4 800 pg/mL范围内呈良好的线性关系, 线性方程为 $\Delta I=4479 \lg C-1516(R=0.9971)$, 检出限为 $0.5 \mathrm{pg} / \mathrm{mL}$. 对 $20 \mathrm{pg} / \mathrm{mL} \mathrm{MUC1}$ 平行测定 5次, 相对标准偏差为 $3.6 \%$. 电化学发光强度的变化值与 MCF-7细胞浓度的对数在 30 5.0 $\times 10^{4} \mathrm{cells} / \mathrm{mL}$ 范围内呈良好的线性关系, 线性方 程为 $\Delta I=3159 \lg C_{\mathrm{cell}^{-}}-3968(R=0.9988)$, 检出限为 9 cells/ $\mathrm{mL}$. 对 $5.0 \times 10^{3}$ cells $/ \mathrm{mL}$ MCF-7细胞平行测定 5 次, 相对 标准偏差为 $4.8 \%$. 与文献值对比 (表 $\mathrm{S} 1$ 和表 $\mathrm{S} 2$ ), 本文建 立的电化学发光适配体生物传感方法具有较低的检出 限. 计算出单个MCF-7 细胞表面的MUC1平均含量为 $21.8 \mathrm{fg} / \mathrm{cell}$ (10900 molecules/cell), 与文献报道值接近 $(9041 \pm 388 \text { molecules/cell })^{[22]}$.

利用该电化学发光适配体生物传感方法分析不同 细胞表面MUC1的含量. 选择MCF-7细胞、 HeLa细 胞、A549细胞、 HCT116细胞和RAW264.7细胞为目 标细胞. 结果如图4所示, 与空白值相比, 不同浓度的 HCT116细胞和RAW264.7细胞存在下, 电化学发光强 度未见明显变化, 说明HCT116细胞和RAW264.7细胞 表面不含或者含有低于检出限的MUC1. 对于不同浓 度的HeLa细胞和A549细胞, 电化学发光强度随着细胞 浓度的增加逐渐增强. 计算三种细胞表面MUC1的平 均含量顺序为MCF-7细胞 $(21.8 \mathrm{fg} / \mathrm{cell})>\mathrm{HeLa}$ 细胞 (5.33 fg/cell)>A549 细胞 $(3.89 \mathrm{fg} /$ cell). MCF-7细胞表 面MUC1的含量明显高于其他几种细胞. 这表明该电 化学发光适配体生物传感方法可用于区别不同细胞表 面MUC1含量. 


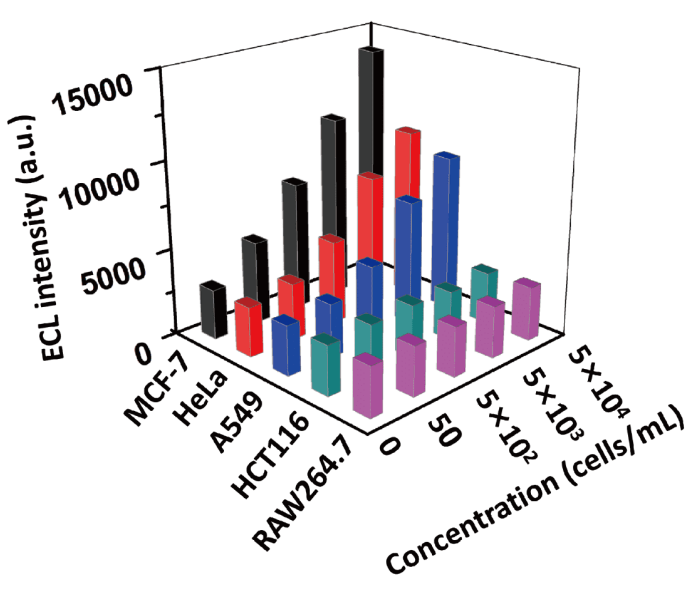

图 4 电化学发光适配体生物传感方法检测不同浓度MCF7 细胞、HeLa细胞、A549细胞、HCT116细胞和RAW264.7 细胞的电化学发光强度柱状图 (网络版彩图)

Figure 4 Histogram of ECL intensity for different concentrations MCF-7 cells, HeLa cells, A549 cells, HCT116 cells and RAW264.7 cells (color online).

\section{5 药物刺激下MCF-7细胞表面MUC1的含量变化}

我们进一步利用该电化学发光适配体生物传感方 法分析外界物质刺激MCF-7细胞后，MCF-7细胞表面 $\mathrm{MUC1} 1$ 的含量变化. 在本实验中, 我们选择了 $72 \mu \mathrm{M}$ 芹 黄素和 $200 \mu \mathrm{M} \mathrm{H}_{2} \mathrm{O}_{2}$ 刺激MCF-7细胞. 两种物质刺激细 胞不同时间后，MCF-7细胞用PI和Annexin V-FITC染 色，利用流式细胞仪分析芹黄素和 $\mathrm{H}_{2} \mathrm{O}_{2}$ 刺激MCF-7细 胞不同时间后细胞的存活状态. 在两种药物刺激的细 胞存活状态基本一致的条件下(图S4和S5)，利用该电 化学发光方法测定MCF-7细胞表面的MUC1含量, 结 果如图5所示. 结果发现，随着芹黄素刺激时间的增加 (4 h, 8 h, 12 h, 16 h, 20 h, 24 h), 电化学发光强度逐渐 降低. 根据标准曲线计算出芹黄素刺激不同时间下 MCF-7细胞表面MUC1的含量分别为17.22 fg/cell (4 h)、 $10.94 \mathrm{fg} /$ cell $(8 \mathrm{~h}) 、 8.87 \mathrm{fg} /$ cell $(12 \mathrm{~h}) 、 5.21 \mathrm{fg} /$ cell $(16 \mathrm{~h}) 、 3.12 \mathrm{fg} / \mathrm{cell}(20 \mathrm{~h}) 、 1.88 \mathrm{fg} / \mathrm{cell}(24 \mathrm{~h})$ (图5(A)). 随着 $\mathrm{H}_{2} \mathrm{O}_{2}$ 刺激时间的增加 $(5 \mathrm{~min}, 10 \mathrm{~min}, 20 \mathrm{~min}$, $30 \mathrm{~min}, 40 \mathrm{~min}, 50 \mathrm{~min}$ ), 电化学发光强度基本保持稳 定. 相对应地, MCF-7细胞表面MUC1的含量分别为 $22.23 \mathrm{fg} /$ cell $(5 \mathrm{~min}), 21.85 \mathrm{fg} / \mathrm{cell}$ (10 $\mathrm{min}), 21.59 \mathrm{fg} /$ cell (20 min), $22.20 \mathrm{fg} /$ cell (30 min), $21.91 \mathrm{fg} / \mathrm{cell}$ (40 min), $22.31 \mathrm{fg} / \mathrm{cell}$ (50 min) (图5(B)),基本保持不变. 结果说 明在芹黄素刺激下MCF-7细胞表面MUC1含量降低, 而在 $\mathrm{H}_{2} \mathrm{O}_{2}$ 刺激下MCF-7细胞表面MUC1含量基本保持
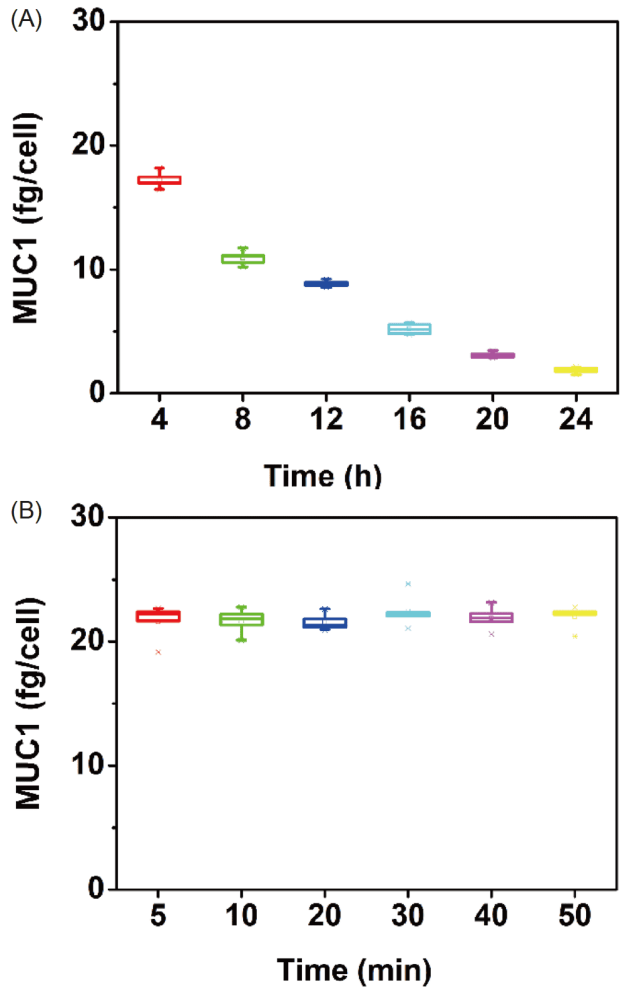

图 5 (A) $72 \mu \mathrm{M}$ 芹黄素刺激不同时间时 MCF-7细胞表面 MUC1含量的动态变化图; (B) $200 \mu \mathrm{M} \mathrm{H} \mathrm{H}_{2}$ 刺激不同时间 时MCF-7细胞表面MUC1含量的动态变化图 (网络版彩图)

Figure 5 (A) Relationship between the amount of MUC1 on MCF-7 cells with the stimulated time of $72 \mu \mathrm{M}$ apigenin; (B) Relationship between the amount of MUC1 on MCF-7 cells and the stimulated time of $200 \mu \mathrm{M} \mathrm{H}_{2} \mathrm{O}_{2}$ (color online).

不变. 因此该方法可用于外界刺激下细胞表面MUC1 含量的实时监测.

\section{4 结论}

本研究基于适配体识别和生物条形码放大策略, 建立了一种高灵敏度的电化学发光适配体生物传感新 方法, 并应用于MUC1和MCF-7细胞的分析检测. 电化 学发光强度的变化值与MUC1浓度的对数在 $4-800 \mathrm{pg} / \mathrm{mL}$ 范围内呈良好的线性关系, 检出限为 $0.5 \mathrm{pg} / \mathrm{mL}$. 电化 学发光强度的变化值与 MCF-7 细胞个数的对数在 30 5.0 $\times 10^{4}$ cells $/ \mathrm{mL}$ 范围内呈良好的线性关系, 检出限 为 9 cells $/ \mathrm{mL}$. 该电化学发光分析方法成功应用于区别 和检测不同细胞表面MUC1的含量和监测在外界物质 刺激下MCF-7细胞表面MUC1的动态变化. 结果发现, MCF-7细胞表面MUC1蛋白的含量明显高于 HeLa细 
胞、A549细胞、HCT116细胞和RAW264.7细胞; 在芹 黄素刺激下MCF-7细胞表面MUC1含量降低，而在 $\mathrm{H}_{2} \mathrm{O}_{2}$ 刺激下MCF-7细胞表面MUC1含量基本保持不
变. 本研究为高灵敏度检测细胞表面蛋白质含量提供 了新方法, 为药物筛选提供了新思路, 将促进电化学 发光分析法的应用.

\section{补充材料}

本文的补充材料见网络版chemcn.scichina.com. 补充材料为作者提供的原始数据, 作者对其学术质量和内容负责.

\section{参考文献}

1 Liu N, Wang Y, Hu X, He B, Qu G, Shi J, Hu L, Jiang G. Sci Sin-Chim, 2018, 48: 1217-1225 (in Chinese) [刘念, 王园园, 胡新笑, 何滨, 曲广波, 史建波, 胡立刚, 江桂斌. 中国科学:化学, 2018, 48: 1217-1225]

2 Dennis JW, Nabi IR, Demetriou M. Cell, 2009, 139: 1229-1241

3 Kufe DW. Nat Rev Cancer, 2009, 9: 874-885

4 Ferreira CSM, Papamichael K, Guilbault G, Schwarzacher T, Gariepy J, Missailidis S. Anal Bioanal Chem, 2008, 390: 1039-1050

5 Liu S, Xu N, Tan C, Fang W, Tan Y, Jiang Y. Anal Chim Acta, 2018, 1018: 86-93

6 Hui J, Bao L, Li S, Zhang Y, Feng Y, Ding L, Ju H. Angew Chem Int Ed, 2017, 56: 8139-8143

7 Yang D, Liu M, Xu J, Yang C, Wang X, Lou Y, He N, Wang Z. Talanta, 2018, 185: 113-117

8 Ma C, Liu H, Zhang L, Li H, Yan M, Song X, Yu J. Biosens Bioelectron, 2018, 99: 8-13

9 Lin C, Zheng H, Huang Y, Chen Z, Luo F, Wang J, Guo L, Qiu B, Lin Z, Yang H. Biosens Bioelectron, 2018, 117: $474-479$

10 Jiang MH, Li SK, Zhong X, Liang WB, Chai YQ, Zhuo Y, Yuan R. Anal Chem, 2019, 91: 3710-3716

11 Wang JX, Zhuo Y, Zhou Y, Yuan R, Chai YQ. Biosens Bioelectron, 2015, 71: 407-413

12 Wang N, Wang Z, Chen L, Chen W, Quan Y, Cheng Y, Ju H. Chem Sci, 2019, 10: 6815-6820

13 Qi H, Zhang C. Anal Chem, 2020, 92: 524-534

14 Wu W, Zhu JJ, Ma C. Sci Sin-Chim, 2020, 50: 631-638 (in Chinese) [马诚, 吴婉婉, 朱俊杰. 中国科学:化学, 2020, 50: 631-638]

15 Qi L, Yuan F, Xu G. Sci Sin-Chim, 2018, 48: 914-925 (in Chinese) [启黎明, 袁帆, 徐国宝. 中国科学: 化学, 2018, 48: 914-925]

16 Wu P, Gao Y, Zhang H, Cai C. Anal Chem, 2012, 84: 7692-7699

17 Storhoff JJ, Elghanian R, Mucic RC, Mirkin CA, Letsinger RL. J Am Chem Soc, 1998, 120: 1959-1964

18 Wang X, Zhang T, Wang B, Qi H, Zhang C. J Electrochem, 2019, 25: 223-231 (in Chinese) [王晓飞, 张婷, 王冰, 漆红兰, 张成孝. 电化学, 2019, 25: 223-231]

19 Cui HF, Xu TB, Sun YL, Zhou AW, Cui YH, Liu W, Luong JHT. Anal Chem, 2015, 87: 1358-1365

Wu Z, Liu GQ, Yang XL, Jiang JH. J Am Chem Soc, 2015, 137: 6829-6836

Ma X, Wang X, Zhou M, Fei H. Adv Healthcare Mater, 2013, 2: 1638-1643

Wu MS, Yuan DJ, Xu JJ, Chen HY. Anal Chem, 2013, 85: 11960-11965 


\title{
Electrogenerated chemiluminescence aptamer-based biosensing for the determination of mucin and specific cells based on bio-bar-code amplification
}

\author{
Xiaofei Wang, Honglan Qi ${ }^{*}$, Chengxiao Zhang \\ Key Laboratory of Applied Surface and Colloid Chemistry of Ministry of Education, Key Laboratory of Analytical Chemistry for Life Science of \\ Shaanxi Province, School of Chemistry and Chemical Engineering, Shaanxi Normal University, Xi'an 710062, China \\ *Corresponding author (email: honglanqi@snnu.edu.cn)
}

\begin{abstract}
A highly sensitive electrogenerated chemiluminescence (ECL) aptamer-based biosensing based on bio-barcode amplification was developed for the determination of cell surface proteins and specific cells. MCF-7 cells were used as target cells, mucin (MUC1) was used as target proteins, anti-MUC1 specific aptamers (rcDNA) were used as molecular recognition elements and $\mathrm{Ru}(\mathrm{phen})_{3}{ }^{2+}$ was used as ECL signal molecules. A hairpin DNA (hpDNA) and a rcDNA were self-assembled on the surface of gold nanoparticles (AuNP) by self-assembly technique to obtain the biobar-code probe hpDNA/AuNP/rcDNA. rcDNA was modified onto the surface of gold electrodes to form a biosensing platform. A sandwich complex among rcDNA, target MUC1 (or MCF-7 cells) and hpDNA/AuNP/rcDNA was formed on the surface of electrodes. After Ru(phen $)_{3}{ }^{2+}$ was intercalated into hpDNA, strong ECL signals were generated in the presence of co-reactants at the constant potential of $0.95 \mathrm{~V}$. The increased ECL intensity was proportional to the logarithm of MUC1 concentration in the range of $4 \sim 800 \mathrm{pg} / \mathrm{mL}$ with a detection limit of $0.5 \mathrm{pg} / \mathrm{mL}$. The increased ECL intensity was proportional to the logarithm concentration of MCF-7 cells in the range of $30 \sim 5 \times 10^{4}$ cells $/ \mathrm{mL}$ with a detection limit of 9 cells $/ \mathrm{mL}$. In addition, the developed ECL method was used to discriminate the MUC1 expression on different types of the cells and to monitor the dynamics of MUC1 on the surface of MCF-7 cells under the external drug stimulation, including apigenin and $\mathrm{H}_{2} \mathrm{O}_{2}$. The decline of MUC1 expression on the surface of MCF-7 cells was observed under apigenin treatment while inconspicuous MUC1 expression was observed under $\mathrm{H}_{2} \mathrm{O}_{2}$ treatment.
\end{abstract}

Keywords: electrogenerated chemiluminescence, biosensing, cell analysis, mucin, drug stimulation

doi: $10.1360 /$ SSC-2020-0193 